\title{
Erratum
}

Oper Orthop Traumatol 2018 $30: 388$ https://doi.org/10.1007/s00064-018-0569-1

Published online: 14 September 2018

c) Springer Medizin Verlag $\mathrm{GmbH}$, ein Teil von Springer Nature 2018

CrossMark

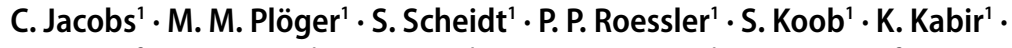

C. Jacobs ${ }^{2}$ - D. C. Wirtz ${ }^{1}$. C. Burger' ${ }^{1}$ R. Pflugmacher ${ }^{1} \cdot$ F. Trommer ${ }^{3}$

' Klinik und Poliklinik für Orthopädie und Unfallchirurgie, UniversitätsklinikumBonn, Bonn, Germany

${ }^{2}$ Poliklinik für Kieferorthopädie, Universitätsklinikum Jena, Jena, Germany

${ }^{3}$ Klinik für Unfallchirurgie und Orthopädie, Luisenhospital Aachen, Aachen, Germany

\section{Erratum to: Three-dimensional thoracoscopic vertebral body replacement at the thoracolumbar junction}

\section{Erratum to:}

Oper Orthop Traumatol 2018

https://doi.org/10.1007/s00064-018-

0559-3

The article was wrongly published under the article type "Review". Please note that the article is an "Original Paper".

The publisher apologizes to authors and readers.

\section{Corresponding address}

\section{Dr. C. Jacobs}

Klinik und Poliklinik für Orthopädie und Unfallchirurgie, UniversitätsklinikumBonn Sigmund-Freud-Str. 25, 53127 Bonn, Germany Cornelius.Jacobs@ukbonn.de
The online version of the original article can be found under https://doi.org/10.1007/s00064018-0559-3. 